\title{
Global Workforce Diversity Management: Challenges across the World
}

\author{
Daniela Kharroubi ${ }^{1, *}$ \\ ${ }^{1}$ VSB-Technical University of Ostrava, Faculty of Economics, Sokolska trida 33, 70200 Ostrava, \\ Czech Republic
}

\begin{abstract}
.
Research background: The increased integration of global workforce from different countries of the multicultural world is a phenomenon which is lately observable in the labour market, i.e. people with different beliefs and backgrounds are interacting due to the world's rapid globalization. However, maintaining a positive workplace in companies has been one of the essentialities that they work on in order to build employer's good brand. Many articles had been written on diversity management, but there were rare researches done on global workforce diversity management.

Purpose of the article: The aim of this article is to review recent literatures, analyse publications in the field of diversity management and to provide an insight on the challenges facing human resources management on a global basis, especially in the Czech Republic.

Methods: This article provides a comprehensive review of quantitative, qualitative and theoretical studies published in journals and distinguishes articles that fall within the search criteria.

Findings \& Value added: Human resources management in most companies put an effort on to increase diversity and to endorse inclusion. The target groups for diversity efforts differ according to the geographical region. Whilst most countries, particularly in Europe and North America have a main insistence on retaining and promoting gender equality. These findings won't only benefit academicians but also managers and potential researchers, because they will be able to acknowledge the various aspects about global workforce diversity management.
\end{abstract}

Keywords: Global workforce; Diversity management; Czech Republic

JEL Classification: $M 14 ; O 15 ; O 57 ; Y 3$

\section{Introduction}

Rapid developments in science and technology; that are essential ingredients of globalization, make diverse workforce to become a reality in organizations nowadays. In other words,

${ }^{*}$ Corresponding author: daniela.kharroubi@vsb.cz 
globalization has given an upswing to a number of factors which in its turn caused the diversity in the labour market. These factors included [1]: demographical changes, decreasing amount of manpower, increasing request to manpower within organizations, growing employment of women, greater inclusion of migrants and people with disabilities into the workplace.

In this regard, organizations had to adopt a global approach in order to survive in the global marketplace and started to seek for a more dynamic cultural model. Hence, organizations began to accept and value the global workforce within the companies' employees who include members of a variety of ethnical, religious, racial and gender backgrounds [2].

Consequently, diversity management as a managerial approach emphasizes the variety of workforce in the workplace while indicating an impact on group-level outcomes as manifested in team performance and social integration [3]. Diversity management falls under the area of human resources management and promotes the involvement of workforces from different cultures, religions and backgrounds in the organization's structure. Thus, firms with diversity management are likely to consider more options and generate more ideas for launching new competitive move and which in its turn increases their ability to recognize and exploit opportunities for developing competitive actions and thus to concatenate numerous short-lived competitive advantages that lead to superior performance [4]. Almost $63.3 \%$ of companies have diversity management nowadays, which is $20 \%$ more than two years ago [5].

Most managers are convinced that when diversity is properly managed, it offers the organization a competitive advantage. Hence, practices that are associated with insider status, including sharing information, participation in decision making, and having voice, are reflected in measures of inclusion, i.e., on increasing the employee's perceptions of inclusion [6]. In this context, Gilbert et al. [7] mentioned that achieving an attractive image in the business world is eye-catching for new potential workers and one of the most important competitive advantages that allows the acquisition of unique human resources, richer knowledge of customers, cultural sensitivity and consistently reaching more efficient results through marketing efforts, creativity, innovation and so forth. Meanwhile, Keil et al. [3] stated that strengthening cultural values within the organization may lead to improve the organization's reputation while gaining better possibilities for attracting highly talented people and improving the motivation and performance of potential employees.

However, in order for the organizations to remove all decimations and differences that surround the workplace, they had to implement various policies and programs to tolerate equality among workers.

The aim of this article is to review recent literatures, analyse publications in the field of diversity management and to provide an insight on the challenges facing human resources management on a global basis, especially in the Czech Republic.

The second part of this paper provides a theoretical background into the concept of diversity management. The third part describes the methodology used in this paper. The fourth part concentrates on the global basis of diversity management and provides a continental comparison. Subsequently, this part specifies information about Czech Republic's diversity management. The fifth part discusses and summarizes the main challenges facing the HRM world widely. And finally, the conclusion provides a summary on the area of diversity management.

\subsection{Literature review}

Mor Barak [8] refers diversity management to: "the voluntary organizational actions that 
are pointed to form a greater inclusion of employees from various backgrounds into the formal and informal organizational structures through deliberate policies and programs".

The term "diversity management" was highly propagated by the publication of Kandola and Fullerton in 1994 [9]. Since then, it has become the typical label in organizations, especially in the US, for policies and practices that head toward "equal opportunities" [10]. However, equality policies have a long history in the employment policy, i.e., since the 1980s, they have been followed by organizations with the introduction of Sex Discrimination Act (1975) and the Race Relations Act (1976).

Most of the diversity literature comes from the United States and meanwhile it can be useful for conceptual debates, it is important to acknowledge that these debates occurred in different economic, social, legal, and historical contexts and they are not entirely transferable to the European context [10]. For instance, the US policy makers paid more attention to redressing ethnic advantage, as a result of the larger minority ethnic population, slavery and racial segregation to avoid widespread civil disturbance. Within Europe, the progress of multiracial society has origins in post-war and government-sponsored immigration [11].

Within the globalization of the economy, diversity management no longer refers solely to the heterogeneity of the workforce of one nation but to the composition of the workforce. In this regard, we recognize two types of diversity management within multinational organizations [8]. The first type is intranational diversity management that refers to managing diverse workforces within a single national organizational context. E.g., a company institutes policies and training programs to improve employment opportunities of minority groups or recent immigrants. The second type, cross-national diversity management, refers to managing diverse workforces composed from different countries. For example, a Japanese company with a branch in the Czech Republic, establishes policies and training programs, and therefore applies them in its subsidiaries. Each of these types experiences different challenges and has to take into consideration the laws and the social norms of each country. In this context, Cox [12] distinguished that the challenge of diversity is not unassumingly to have it but to create conditions in which its potential to be a performance barrier is minimized and its potential to enhance performance is maximized. Furthermore, he states that diversity management creates a competitive advantage in areas such as marketing, resource acquisition and problem solving. However, it is important to consider researches on the global context of diversity management, which have both negative and positive consequences, in addition to no change or a nuanced approach to the link of diversity management and organizational outcomes [13].

Furthermore, positive aspects of diversity in the workplace embrace the possibility of influencing stereotypes and improving equal opportunities in the workplace and in society. Differences between people can also cause a broader scale of experience, creative thinking and innovative solutions to problems [14]. On the other hand, the emergence of possible misunderstandings, suspicions and conflicts which in its turn could lead to the absence of employees, their low morale work or loss of competitiveness. Besides the problems in the social integration of employees; there is the language barrier, which gives rise to the possibility of weakening the communication flow in organizations and the emergence of communication interferences or risks stemming from cultural differences [1].

It is thus necessary, first and foremost, to escalate the awareness of executives on diversity and on the importance of good cooperation for the success of the organization. Which means to manage diversity from the top down, which in its turn demands a change in the organization culture on all of its levels. In terms of strategic approaches to diversity management, multinational corporations (MNCs) adopt an approach that shows an international orientation and strategy. Consequently, their management's philosophy recognizes diversity as critical for organizational success. In other words, top management's commitment to diversity should be exposed in its vision, mission, and business strategy in 
order to eliminate psychological and operational barriers [15]. If such duty is inconstant to the current organizational culture, then a significant culture change may be necessary to create an atmosphere of communal respect of all employees. Meanwhile, at the tactical level, a range of diversity policies should be devised in order to support this management philosophy. However, measuring employees' perception of existing practices in the area of diversity management and their expectations may be accompanied to assist policy development. At the operational level, the HR diversity policies are implemented directly at the workplace, which include mostly educating employees, identity-based networking groups, targeting communications to different affinity group members, flexible employment and support for generating a work-life balance [15]. Grant and Schneider [16] found that line managers restatements on organizational policy, especially on racial equality are sometimes at odds with employees' opinions of organizational practice. Therefore, the involvement of the line management in the decision-making process is a necessity in order to implement effective diversity management. Figure 1 summarizes the implementation of diversity management at all levels in an organization.

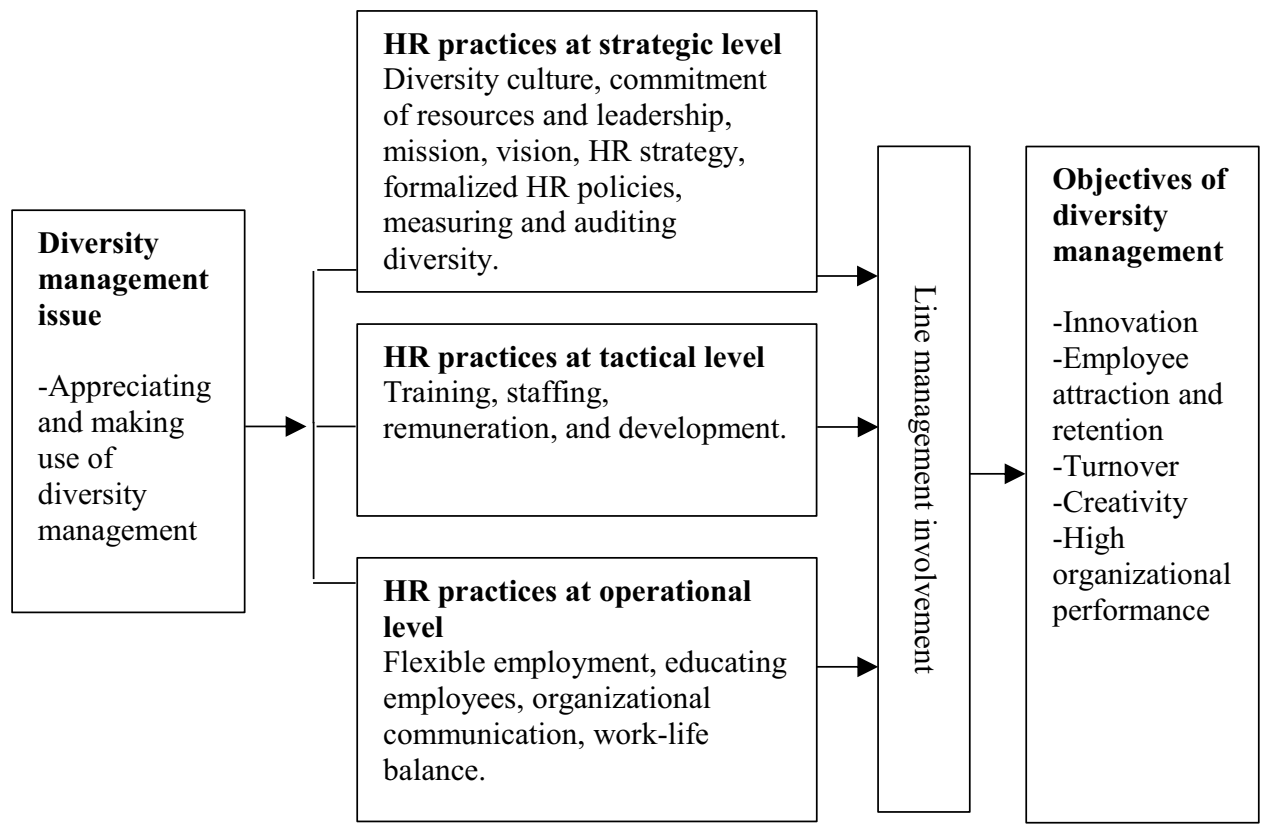

Fig. 1. A framework of diversity management implemented at all managerial levels. Source: Shen et al. (2009, page 245), modified.

Nevertheless, diversity management in domestic and multinational corporations is not on the same level as of their strategic decision-making and cross-national coordination activities. Even though domestic corporations are starting to get engaged in the area of diversity management nowadays, the same cannot be said about global diversity management. Thus, it is a platitude to underline that a growing number of international, multinational, and global organizations have now departments which specialize on global diversity management. Whilst, the domestic diversity management function has a more traditional role of assembling a national policy and accompanying the effective implementation of the policy in a concrete country. The difference between diversity management activities in domestic and MNCs is mainly observable in North America and in Europe, where the practices of diversity management have acknowledged a development.

However, the ever-increasing of the globalization has placed the management of cultural differences into the HR agendas. The key to assigning the advantages of multiculturalism and 
eluding its consequences is to create an organization in which members of all socio-cultural backgrounds contribute and achieve their full potential. To achieve this, HR managers face a dichotomy in maintaining a balance between meeting the objectives of the organization, on one hand, and retaining the individual cultures of employees on the other [2]. Experts agree that a person's job match is positively related to job satisfaction and job performance, in particular a person's job match mediates the relationship between workforce diversity management and employees' outcomes [17]. Cox and Blake [18] claimed that the benefits of effective diversity management include reducing turnover, absenteeism and attracting the best candidates as the labour market shrinks. Moreover, Cox has provided a conceptual framework (figure 2) showing the impact of diversity on the organizational and on individual outcomes.

\begin{tabular}{|c|c|c|}
\hline $\begin{array}{l}\text { Diversity Climate } \\
\text { Individual factors } \\
\text {-Identity structures } \\
\text {-Prejudice } \\
\text {-Stereotyping } \\
\text {-Personality } \\
\text { Group/Intergroup } \\
\text { factors } \\
\text {-cultural differences } \\
\text {-Ethnocentrism } \\
\text {-Intergroup conflict } \\
\text { Organizational } \\
\text { factors } \\
\text {-Culture and } \\
\text { acculturation process } \\
\text {-Structural integration } \\
\text {-Informal integration } \\
\text {-Institutional Bias in } \\
\text { HR }\end{array}$ & $\begin{array}{l}\text { Individual career } \\
\text { outcomes } \\
\text { Affective outcomes } \\
\text {-Job/career satisfaction } \\
\text {-Job involvement } \\
\text { Achievement } \\
\text { outcomes } \\
\text {-Job performance } \\
\text { ratings } \\
\text {-Compensation } \\
\text {-Promotion } \\
\text {-Horizontal mobility } \\
\text { rates }\end{array}$ & \begin{tabular}{|l}
$\begin{array}{l}\text { Organizational } \\
\text { effectiveness }\end{array}$ \\
First level \\
-Attendance \\
-Turnover \\
-Productivity \\
-Work quality \\
-Recruiting success \\
-Creativity \\
-Problem solving \\
-Workgroup \\
-cohesiveness and \\
communication \\
\\
Second level \\
-Market share \\
-Profitability \\
-Achievement of \\
formal organizational \\
goals
\end{tabular} \\
\hline
\end{tabular}

Fig. 2. An interactional model of the impact of diversity on the individual outcomes and the organizational effectiveness. Source: Cox (1994, page 32), modified.

This model (Fig. 2.) shows that person's affiliations such gender, race and age can be analyzed on three levels, i.e. individual, group and organizational, which in turn define the climate of diversity in the organization. This climate influences individual and organizational outcomes as effectives or achievement outcomes. Thus, these outcomes influence organizational factors such as productivity and work quality.

The next part of this article concentrates on the methodology used, the summarization of the global basis of diversity management and on providing a continental comparison. Subsequently, this part specifies information about Czech Republic's diversity management. 


\section{Methodology}

A systematic review of the literature on diversity management was carried out through a relevant search of keywords. Specific keywords like global workforce diversity, diversity management, managing diversity were searched, followed by certain criteria. Primarily, to access the relevant articles, the author searched relevant databases (WoS, Scopus, SAGE).

This paper provides a comprehensive review of quantitative, qualitative, and theoretical studies published in journals and distinguishes articles that fall within the search criteria. It concentrates on the global diversity management and makes the required regional comparisons. Mostly, it will be based on the results commissioned by Forbes Insights and conducted by Oxford Economics, which provide a unique ranking of employee diversity across 50 global economies, 14 industrial sectors and nine occupations.

\section{Results: Diversity management across the world}

\subsection{Europe}

Europeans are exceedingly engaged in promoting diversity and inclusion, thus $37 \%$ of European respondents strongly promote diversity, compared with 30\% in Asia and 34\% in North America [19]. Furthermore, debating about equal opportunity laws is a powerful business rational for diversity initiatives in Europe than elsewhere. Where fifty percent of European respondents claim that legal obedience is the major business rational, compared to Asian respondents 33\% and North American respondents 37\% [19].

One of the most outstanding economic events in Europe in recent times has been the access of large numbers of women into the workforce. In advanced countries, this growth has been fast. Today, three countries are with the highest percentage of female workers Iceland $78 \%$, Denmark - 75\% and Norway - 71\% [19]. Although the gender gap is narrowing in other G8 (the group of eight) countries.

In order to keep an emphasis on gender diversity, European companies focus their diversity programs on work-life balance issues. Hence, $42 \%$ of European respondents say that they focus on such measures [19].

The lowest rates of participation in the workforce are among older workers in Europe. Of the fifty nations in the index, the bottom twenty are all in Europe. The only exception is Iceland, which ranks third, $35 \%$ in economic activity for those over 65 [19]. The five lowest ranking countries are Hungary, Belgium, Slovakia, France and Luxembourg [19]. However, these rates could change if more European countries adopt policies requiring older workers to engage in the workforce.

Correspondingly, European companies fall short in regard to include ethnic minorities in their ranks. In the survey issued by Oxford Economics, only $49 \%$ of Europeans say ethnic minorities are included in the workforce [19].

\subsection{North America}

The United States ranks $9^{\text {th }}$ on the index D\&I (diversity and inclusion), scoring realistically well with most measures of diversity. North American companies are more tolerable to the idea that strong diversity measures are needed. Although most U.S. multinational corporations have substantial workforce diversity management programs in their U.S. operations, they are only beginning to consider parallel efforts in their overseas subsidiaries and affiliates [20]. 
However, there are plain differences in the diversity of employees across different occupations and industries in the US. E.g., over seven in ten human resources specialists are women, and the allocation of both black and African Americans and Hispanic or Latinos also is well above average. In this context, female labor market participation has improved in the US (59\%), but still falls behind the leading European countries, for example, Iceland and Denmark [19].

Moreover, in the US, both gender and ethnic diversity decrease severely, the higher one climbs the occupational ladder. Of the 1.5 million chief executives in the US, just one quarter are women and only one in ten are ethnic minorities. This sorts the CEO alongside farmers and military personnel, one of the least diverse occupations of all [19].

Conversely, North American companies' managements are also more optimistic on the need to increase diversity in the very senior ranks. Thus, $28 \%$ of North American companies report a general attitude of indifference to diversity at the top ranks, compared to Asia $-36 \%$ and Europe - 32\% [19]. In its place, North American companies give more responsiveness to the presence of racial minorities and ethnic minorities.

\subsection{Asia}

Countries showing at the bottom of the rankings of diversity and inclusion include China and Indonesia, which are large emerging economies with a substantial local labor supply. Workforces with disabilities, for example, are in far worse situations than elsewhere. Nearly $64 \%$ of Asian respondents say that disabled people are underrepresented in their organization compared to 52\% in North America and 56\% in Europe [19]. The countries with the lowest proportion of women are Japan (0.9\%) and Korea (1\%) [19]. It is unusual for such a an advanced economy as Japan to appear so far down on the rankings, but the culture has an insular approach to board room diversity; the majority of jobs are filled by Japanese men, with few women or non-Japanese.

\subsection{Middle East}

In Middle East, diversity of nationality is at the top of the schema. Particularly in oil rich Arab nations, the focus is on hiring more local nationals to replace expatriate workers. For instance, the UAE recorded the largest stock of migrant labor by a considerable distance. It is important to note that the UAE is very different from other countries. Emirati nationals only account for $19 \%$ of the total UAE population, much lower than other Middle Eastern states such as Bahrain and Oman, where national citizens account for $62 \%$ and $80 \%$ of the population, respectively [19]. Many of the workers are Indian or Pakistani migrants employed in the construction industry, as large-scale developments in the UAE are completed at a rapid pace. However, the local office economy is also dominated by expatriates from around the world, including many of the highest paid jobs. Immigration on this scale creates both benefits and costs: the UAE government now acknowledges the need to increase the share of nationals within its labor market. However, it is important to note that in the case of UAE, low economic activity rates are amongst female nationals (28\%) compared to female migrant labor $(47 \%)$ [19].

\subsection{Czech Republic}

The results of the research conducted by Urbancová et al. [21] showed that most of the addressed organizations in the Czech Republic do not apply the concept of Diversity Management (57.4\%) and that most organizations that apply the concept are from the tertiary 
sector $(67.5 \%)$. Another research managed by Safrankova \& Sikyr [22] showed that SMEs (small medium enterprises) are able to effectively and efficiently prevent gender and age discrimination of employees in the Czech Republic, however, they should focus more on creating and maintaining employment opportunities and working conditions regarding the natural diversity of people. Furthermore, this research proved diversity management policies and practices in SMEs should be focused on diverse employee selection, evaluation, compensation, and development. These activities may then enable SMEs to attract, employ, and develop gender and age diverse groups of people. Moreover, the Czech Republic was one of the eight countries who opposed a proposed EU regulation from the European Commission in 2012 that set a $40 \%$ quota on the mandatory representation of women in the management structures of selected companies [23].

\section{Discussion}

As multicultural organizations become more global in their maneuvers, the difficulties resulting from the cultural diversity of the organization's workforce become more apparent to HR managers. In order to address these apprehensions, Doktor, Tung and von Glinow [24] propose that theorists should develop models that capture these realities. Thus, in terms of global diversity management, there is a need for new and systematic conceptual frameworks, as well as new programs for training and educating the new cohort of global diversity managers.

Even though, a number of models were developed on global diversity management, but there still remain challenges in attaining effective global diversity strategies and practices. Managing multicultural organizations is a complex issue, because managers face formidable challenges while building a multicultural organization that values diversity. These challenges appear as a result that not everyone in the organization respects diversity. As most of the people feel comfortable with those like themselves and diversity may impact the level of comfort.

Nevertheless, the integration of migrants is one of the biggest challenges to European Union countries today, and it signifies a serious challenge to the management of European diversity. While migrant integration remains the primary responsibility of nation states, EU policies are important with regard to knowledge exchange, its promotion, and the monitoring of integration practices [25]. In EU treatise the integration of migrants is a key mechanism to maximize the opportunities and contributions that migration can make to EU development, while employment is central to the participation of migrants. European Union legislation affords a strong anti-discrimination framework and emphasizes equal opportunities.

Likewise, aging populations are a significant challenge to governments, as they affect economic growth, trade, migration, and put strain on pension systems and other social programs [19]. To counter this, countries such as the U.S., U.K. and Germany have acknowledged plans to elevate the threshold for age-related entitlement programs. Having employees work longer has two obvious economic benefits: it boosts output and reduces the period of time over which pensions need to be paid [19].

\section{Conclusion}

Diversity and inclusion have started to be accepted as a collective business topic worldwide. The reasons differ from moral concerns to profitability. Thus, most companies worldwide put an effort to increase diversity and to promote inclusion. The target groups for diversity efforts fluctuate in different geographies, but most regions and mainly in Europe and North America, have an emphasis on attracting, retaining and promoting women. However, several 
approaches seem common to all regions. They include putting the customs at the top of the organization, conducting ongoing trainings to promote better understanding between employees with various backgrounds and creating opportunities for minority groups. However, as the workforce becomes more diverse, tensions over cultural issues are expected to occur. Cultural conflicts can be a significant drain on the energy of the people involved, especially minority workforces who are more likely to feel overloaded by the differences. For organizations, changes in workforce demographics are subject to both opportunities and challenges. Although, the organization that achieves the conditions of a multicultural organization will contribute to an environment in which all associates can achieve their maximum potential, and in which the value of diversity can be fully realized.

Finally, in line with these findings, the concept of diversity management in the Czech Republic should be more investigated with field studies. Diversity management implications in Czech companies, the process of these practices and the consequences of these approaches on the outcomes of the companies can be an initial point for future research studies.

This research was supported within the project of the Student Grant Competition at the Economic Faculty of VŠB-Technical University Ostrava SP2020/33.

\section{References}

1. Urbancová, H., Čermáková, H., Vostrovská, H. (2016). Diversity management in the workplace. Acta Universitatis Agriculturae et Silviculturae Mendelianae Brunensis, 64(3), 1083-1092.

2. Edewor, P. A., Aluko, Y. A. (2007). Diversity management, challenges and opportunities in multicultural organizations. The International Journal of Diversity in Organisations, Communities and Nations, 6(6), 189-195.

3. Horwitz, K. S., Horwitz, B. I. (2007). The Effects of Team Diversity on Team Outcomes: A Meta-Analytic Review of Team Demography. Journal of Management, 33(6), 987-1015.

4. Andrevski, G., Richard, C. O., Shaw, D. J., Ferrier, J. W. Racial Diversity and Firm

Performance: The Mediating Role of Competitive Intensity. Journal of Management, 40(3), 820-844.

5. Charta der Viefalt. (2018). Diversity management studie. Charta der Viefalt. Retrieved from: https://www.charta-der-vielfalt.de/uploads/tx_dreipccdvdiversity/Diversity\%20Studie\%202018.pdf

6. Shore, M.L., Randel, E. A., Chung, G. B., Dean, A. M., Ehrhart, H. K., Singh, G. (2011). Inclusion and Diversity in Work Groups: A Review and Model for Future Research. Journal of Management, 37(4), 1262-1289.

7. Gilbert, J. A., Stead, B. A., Ivancevich, J. M. (1999). Diversity management: A new organizational paradigma. Journal of Business Ethics, 21(1), 61-76.

8. Mor Barak, M. (2015). Managing diversity: Toward a globally inclusive workplace. London (UK): SAGE Publications Ltd.

9. Kandola, R., Fullerton, J. (1994). Managing the mosaic. London: CIPD.

10. Kirton, G., Greene, A. M. (2010). The dynamics of managing diversity. Netherlands: Elsevier Ltd.

11. Solomos J. (1989). The Politics of Immigration since 1945. In: Race and Racism in Contemporary Britain. London: Palgrave. 
12. Cox, T. (2001). Creating the multicultural organization: A strategy for capturing the power of diversity. University of Michigan business school management series. New Jersey: Wiley.

13. Thomas, R. T., Thomas, D. A., Ely, R. J., Meyerson, D. (1996). Making differences matter: A new paradigm for managing diversity. Harvard Business Review on managing diversity, 74(5), 79.

14. Kearney, E. (2013). Diversity und innovation. Kreativität, innovation, entrepreneurship. Wiesbaden: Gabler Verlag.

15. Shen, J., Chanda, A., D'Netto, B., Monga, M. (2009). Managing diversity through human resource management: an international perspective and conceptual framework. The International Journal of Human Resource Management, 20(2), 235-251.

16. Sanglin-Grant, S., Schneider, R. (2000). Moving on up? Racial equality and the corporate agenda. Runnymede Trust. Retrieved from: https://www.schneiderross.com/wp-content/uploads/2012/07/Moving-on-Up.pdf

17. Li, W., Wang, X., Haque, J. Md., Shafique, N. M., Nawaz, Z. M. (2020). Impact of Workforce Diversity Management on Employees' Outcomes: Testing the Mediating Role of a person's Job Match. SAGE Journals, 10(1), 1-16.

18. Cox, T., Blake, S. (1991). Managing cultural diversity: Implications for organizational competitiveness. Academy of Management Executive, 5(3), 45-56.

19. Oxford Economics. (2019). The global diversity report. Forbes Insight. Retrieved from:

https://d2rpq8wtqka5kg.cloudfront.net/128931/open20110106120000.pdf?Expires=1 606052576\&Signature=ZBzvjkJnXJTuUxaj1JqDaUNrGfDknm 0TI5YshG1BUtYuT xXkzb2FeFpia1eKt-

juF7z01zABlyPSmKshtdnu9RLgFIFIjyGj 0DZm0wt7NMHGQo6PvQKis1ecV YB 0h9CAQTO6VLCHMe1MVquAK55eElaxwdhCTGcBviZJhHaMvKUx8xZgK0YzG qVdSyQ8kCEObBqegF1gvh2G3TMfKjiWkHXDpVYEd6hz4EDgcua6FaGIkqldv66 UU6SLmtgzvPo4RzX2JeE7jDYBeFMkW2U3HIjpbcq3BQko5va4juPUWFufwJVQ ejcMyPvNzAuunP1BgHWMEyNtciTJu9cAV9g_\&Key-PairId=APKAJVGCNMR6FQV6VYIA

20. Egan, L. M., Bendick, M. Jr. Workforce Diversity Initiatives of U.S. Multinational Corporations inEurope. (2003). Thunderbird International Business Review, 45(6), 701-727.

21. Urbancová, H., Čermáková, H., Vostrovská, H. (2015). Using of diversity management in Czech organizations. In P. Jedlicka (Ed.), Proceedings of the 13th International Scientific Conference on Hradec Economic Days (pp.281-287). Univ Hradec Kralove: Hradec Economic Days.

22. Safrankova, J.M., Sikyr, M. (2019). Management and diversity management in SMEs in the Czech Republic. Marketing and Management of Innovations, 1, 221-228.

23. Leseticky, O., Hajdikova, T., Komarkova, L. (2016). Gender diversity in the management of hospitals in Czech Republic. In Acad Conf LTD (Eds.), Proceedings of the International Conference on Management Leadership and Governance (pp.202209). Saint Petersburg: Acad Conf LTD.

24. Doktor R., Tung R. L., Von Glinow M. A. (1991). Future directions for management theory development. The Academy of Management Review, 16(2), 362-365.

25. Tomic, T. V. (2018). The challenges of diversity management to migrant integration in the European Union. Croatian and comparative public administration, 18(2), 223246. 